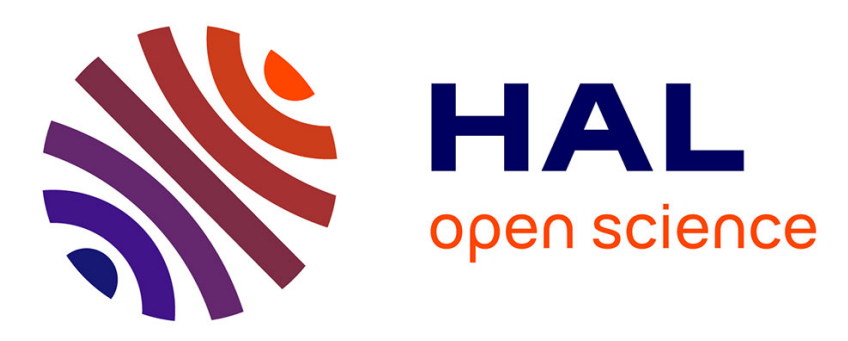

\title{
Influence of alternating field frequency on enhanced photorefractive gain in two-beam coupling
}

Claudine Besson, Jean-Michel Jonathan, André Villing, Gilles Pauliat, Gérald Roosen

\section{- To cite this version:}

Claudine Besson, Jean-Michel Jonathan, André Villing, Gilles Pauliat, Gérald Roosen. Influence of alternating field frequency on enhanced photorefractive gain in two-beam coupling. Optics Letters, 1989, 14 (24), pp.1359-1361. hal-00856623

\section{HAL Id: hal-00856623 \\ https://hal-iogs.archives-ouvertes.fr/hal-00856623}

Submitted on 2 Sep 2013

HAL is a multi-disciplinary open access archive for the deposit and dissemination of scientific research documents, whether they are published or not. The documents may come from teaching and research institutions in France or abroad, or from public or private research centers.
L'archive ouverte pluridisciplinaire HAL, est destinée au dépôt et à la diffusion de documents scientifiques de niveau recherche, publiés ou non, émanant des établissements d'enseignement et de recherche français ou étrangers, des laboratoires publics ou privés. 


\title{
Influence of alternating field frequency on enhanced photorefractive gain in two-beam coupling
}

\author{
C. Besson, J. M. C. Jonathan, A. Villing, G. Pauliat, and G. Roosen
}

Institut d'Optique Théorique et Appliquée, U.A. Centre National de la Recherche Scientifique, Centre Universitaire d'Orsay, Bâtiment 503, B.P. 147, 91403 Orsay Cédex, France

Received February 6, 1989; accepted October 13, 1989

\begin{abstract}
We derive an analytic expression describing the intensity and field frequency dependence of photorefractive gain in two-beam coupling under an alternating square-wave electric field. We determine the frequency and intensity ranges over which the gain is maximum and time independent. Experimental results for $\mathrm{Bi}_{12} \mathrm{GeO}_{20}$ crystals are presented.
\end{abstract}

Image processing, ${ }^{1,2}$ beam steering, ${ }^{3}$ and spatial light modulators ${ }^{4}$ are appealing applications of two-wave mixing in photorefractive materials. Semiconductors ( $\mathrm{GaAs}, \mathrm{InP}: \mathrm{Fe})$ and sillenite crystals $\left(\mathrm{Bi}_{12} \mathrm{GeO}_{20}\right.$, $\left.\mathrm{Bi}_{12} \mathrm{SiO}_{20}\right)$ are attractive materials because of their high photosensitivity. Their low diffusion efficiency can be compensated for by applying an ac electric field to the crystal. ${ }^{5}$ This ac field increases the photorefractive-index change and preserves the $\pi / 2$ phase shift between the intensity pattern and the induced index grating. The phase shift is responsible for the steady-state energy exchange between two writing beams. The photorefractive two-beam coupling gain is thereby significantly enhanced.

This amplification technique has been widely studied for the case of an ac field period $T$ much shorter than the time constant of the photorefractive effect. ${ }^{5-8}$ This approach has the advantage of giving a simple analytic expression for the space-charge electric field. However, for practical reasons, ${ }^{9}$ it is important to predict what happens when the time constant of the hologram buildup is close to the period $T$ of the ac field. For instance, for a given power supply, i.e., a given period $T$, it is interesting to determine the fastest photorefractive time constant that we can work with. Therefore we derive a general analytic expression for the space-charge electric field, whose imaginary part is proportional to the two-beam coupling gain. This expression is valid in the quasi-continuous regime for all values of $T$. This study is conducted for a squarewave ac field that provides much larger gains than a sinusoidal ac field.

We employ the band-transport model to analyze the space-charge electric field. ${ }^{10-12}$ We assume a quasicontinuous regime, i.e., the steady state of the spatially nonmodulated part of the electron and hole populations are reached well before the buildup of the photorefractive grating, and that the spatially modulated hole and electron populations are negligible compared to the ionic grating. Since the probe intensity is much less than the pump intensity, the modulation index of the interference pattern is small and the equations for the band-transport model can be linearized. We assume that only one type of donor is responsible for the photorefractive effect. Thus we have the usual firstderivative equation for the complex space-charge electric field $E_{1}$,

$$
\frac{\partial E_{1}}{\partial t}=-\frac{1}{\tau}\left(E_{1}-E_{\mathrm{sc}}\right),
$$

where $1 / \tau$ is a complex constant as defined in Ref. 13 and $E_{\mathrm{sc}}$ is the steady-state space-charge field proportional to the modulation index. The real part of $1 / \tau$ corresponds to the inverse of the grating formation time, and its imaginary part corresponds to the pulsation of the damped oscillation observed and measured in Ref. 13. The terms $1 / \tau$ and $E_{\mathrm{sc}}$ can be extended for two types of charge carrier. ${ }^{11}$

Equation (1) is valid when the applied electric field is constant. Consequently, if the period $T$ of the square-wave electric field $E(t)= \pm E_{0}$ is long compared with the charge carrier lifetime, Eq. (1) can be used to determine the evolution of $E_{1}$ during each half-period of the applied field. Since the rise time of $E(t)$ is small compared with the grating formation time, we neglect variations in the grating during the switchover from $\pm E_{0}$ to $\mp E_{0}$.

The steady-state solution is calculated through recursion. We add the contributions of the electric field to each half-period and find that in the limit the recursion series yields the following expression for the space-charge field at the beginning of each positive half-period:

$$
\begin{aligned}
E_{1 \mathrm{st}}^{+}= & \frac{1}{1-\exp \left[-\frac{T}{2}\left(\frac{1}{\tau}+\frac{1}{\tau^{*}}\right)\right]} \\
& \times\left\{-E_{\mathrm{sc}}^{*}\left[1-\exp \left(-T / 2 \tau^{*}\right)\right]+E_{\mathrm{sc}} \exp \left(-T / 2 \tau^{*}\right)\right. \\
& \times[1-\exp (-T / 2 \tau)]\} .
\end{aligned}
$$

Here the asterisk denotes complex conjugation.

If we take into account the relations

$$
\tau\left(-E_{0}\right)=\tau^{*}\left(E_{0}\right) \text { and } E_{\mathrm{sc}}\left(-E_{0}\right)=-E_{\mathrm{sc}}^{*}\left(E_{0}\right)
$$

at the beginning of each negative half-period we have

$$
E_{1 \mathrm{st}}^{-}=-E_{1 \mathrm{st}}^{+*}
$$


As a consequence of Eq. (1), the temporal evolution of the space-charge field during each positive half-period is given by

$$
\begin{aligned}
E_{1}^{+}(t)= & \operatorname{Im}\left(E_{1 \mathrm{st}}^{+}\right)-\operatorname{Re}\left(E_{1 \mathrm{st}}^{+}\right) \\
& \times \frac{1+\exp \left(-\frac{T}{2 \tau}\right)-2 \exp \left(-\frac{t}{\tau}\right)}{1-\exp \left(-\frac{T}{2 \tau}\right)},
\end{aligned}
$$

where $\operatorname{Re}(c)$ and $\operatorname{Im}(c)$ denote the real and imaginary parts of a complex number $c=\operatorname{Re}(c)+\operatorname{Im}(c)$ and where the origin time $t$ is chosen to be the beginning of each half-period.

Because of the symmetries in Eqs. (3), the imaginary part of the space-charge field oscillates with a period $T / 2$. We thus have from Eq. (4)

$$
\begin{aligned}
\operatorname{Im}\left[E_{1}^{+}(t)\right]= & \operatorname{Im}\left[E_{1}^{-}(t)\right]=\operatorname{Im}\left(E_{1 \mathrm{st}}^{+}\right)-\operatorname{Re}\left(E_{1 \mathrm{st}}^{+}\right) \\
& \times \operatorname{Im}\left[\frac{1+\exp \left(-\frac{T}{2 \tau}\right)-2 \exp \left(-\frac{t}{\tau}\right)}{1-\exp \left(-\frac{T}{2 \tau}\right)}\right] .
\end{aligned}
$$

When the period $T$ is small so that $\operatorname{Re}\left(E_{1 \mathrm{st}}^{+}\right) \ll$ $\operatorname{Im}\left(E_{1 \mathrm{st}}^{+}\right)$, the oscillations disappear and Eq. (4) becomes

$$
E_{1}^{+}(t)=E_{1}^{-}(t)=\frac{\operatorname{Im}\left(E_{\mathrm{sc}} / \tau\right)}{\operatorname{Re}(1 / \tau)} .
$$

This expression was previously derived in Ref. 5 under the assumption that $T \ll[\operatorname{Re}(1 / \tau)]^{-1}$. We now have the more detailed Eqs. (2) and (5) that describe the kinetics of the imaginary part of the space-charge field and thus the gain. The gain depends on the optical intensity (through $\tau$ ) and on the period $T$ of the ac field.

Experimental verification of Eqs. (2) and (5) has been conducted on a $\mathrm{Bi}_{12} \mathrm{GeO}_{20}$ crystal grown at the Université de Bordeaux, Bordeaux, France. The photorefractive parameters of this sample were measured elsewhere ${ }^{14}$ : the predominant charge carriers are holes of diffusion length $L=2.3 \mu \mathrm{m}$, the trap density is $N_{A}=0.8 \times 10^{15} \mathrm{~cm}^{-3}$, and the photoconductivity is $\sigma=$

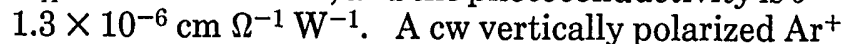
laser $(\lambda=514 \mathrm{~nm})$ is split into two beams incident upon the [i110] crystallographic face. The pump-toprobe beam ratio $\beta=160$, so there is no significant depletion of the strong pump beam. These beams are expanded. The gain is not affected by the diameter of the beams nor by nonuniform illumination of the sample, as is expected for this amplification technique. ${ }^{6}$ The square-wave electric field is applied along the (001) axis through silver-painted electrodes. Its value inside the crystal, determined by electro-optic measurements (as described in Ref. 13 but under an ac field), is $E(t)= \pm 1.2 \mathrm{kV} \mathrm{cm}-1$, less than the applied field by a factor of $0.7-0.8$.

The gain versus field frequency for two different total incident intensities $\left(200 \mu \mathrm{W} / \mathrm{cm}^{2}\right.$ and $3.6 \mathrm{~mW} /$ $\mathrm{cm}^{2}$ ) is plotted in Fig. 1 for this $\mathrm{Bi}_{12} \mathrm{GeO}_{20}$ sample.
The corresponding grating formation times $[\operatorname{Re}(1 /$ $\tau)]^{-1}$ are derived ${ }^{10}$ from the material parameters and take into account the absorption of the material. These formation times are $0.5 \mathrm{sec}$ and $28 \mathrm{msec}$, respectively. Both curves present a plateau whose maximum value $\left(G_{\max }=1.15 \mathrm{~cm}^{-1}\right)$ is intensity independent. In comparison, under a drift process (dc field $E_{0}$ $=1.2 \mathrm{kV} \mathrm{cm}-1$ ), the gain is only $G<0.1 \mathrm{~cm}^{-1}$ for this grating period. The beginning of the plateaus correspond to applied field frequencies comparable to $|\operatorname{Im}(1 / \tau)|$. At low frequencies, the $-3-d B$ cutoff frequencies are 1.8 and $28 \mathrm{~Hz}$, respectively. As expected, since $1 / \tau$ is proportional to intensity, an increase in the intensity increases the frequency of the lower edge of the plateau. There also exists an intensity-independent upper frequency limit. The decrease of the gain may be due to the voltage supply bandwidth that causes the electric-field rise time to be comparable with the grating formation time. Moreover, we are near a frequency region $f \geqslant f_{c}=500 \mathrm{~Hz}$ that is outside the quasi-continuous regime. Indeed, in this sample the recombination time of charge carriers is $22 \mu \mathrm{sec}$, and the index grating evolution during each half-period $T / 2$ is no longer described by Eq. (1). Therefore, we can compare our measurements to the theoretical predictions only for frequencies below $f_{c}$. The theoretical gains are plotted as solid curves in Fig. 1 . They correspond to a space-charge field calculated at the beginning of each half-period. Therefore, they correspond to the lowest points of the dashed segments, which represent the experimental oscillations predicted by Eq. (5). For curves (b), at $f=13 \mathrm{~Hz}$, the predicted gain at the beginning of each half-period becomes negative. However, experimental uncertainties (solid vertical bars) may prevent observation of the sign reversal. We note that the temporal mean value of the

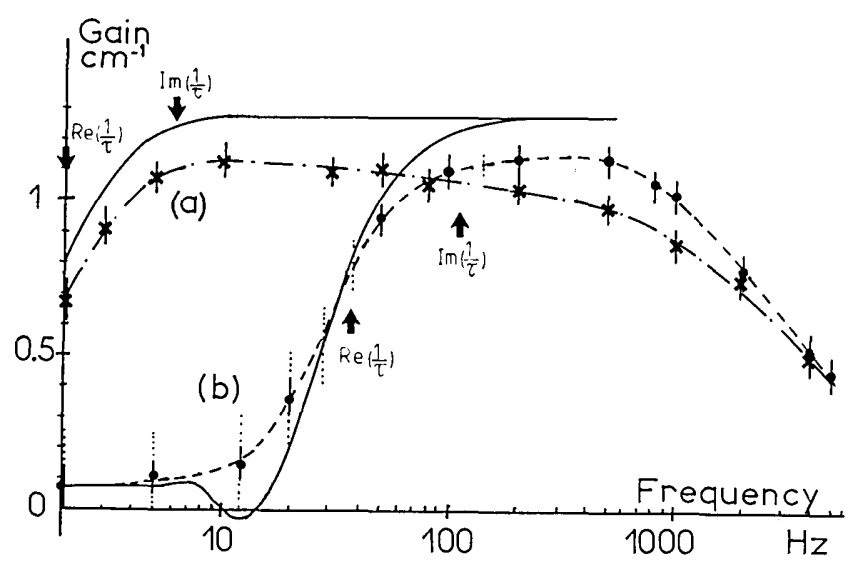

Fig. 1. Coupling gain versus applied field frequency for an undoped $\mathrm{Bi}_{12} \mathrm{GeO}_{20}$ sample with $I_{0}=200 \mu \mathrm{W} / \mathrm{cm}^{2}$ [curves (a)] and $I_{0}=3.6 \mathrm{~mW} / \mathrm{cm}^{2}$ [curves (b)]. On the experimental (dashed) curves, the dotted vertical bars show the amplitude of the temporal oscillations of the gain. The points represent the temporal average values; the solid vertical bars with the points are the estimated experimental errors. Two theoretical (solid) curves are plotted for comparison with the theoretical values of $\operatorname{Re}|1 / \tau|$ and $\operatorname{Im}(1 / \tau)$. They correspond to a space-charge field calculated at the beginning of each half-period. The fringe spacing is $\Lambda=30 \mu \mathrm{m}$, and the applied field $E_{0}= \pm 1.6 \mathrm{kV} / \mathrm{cm}$. 


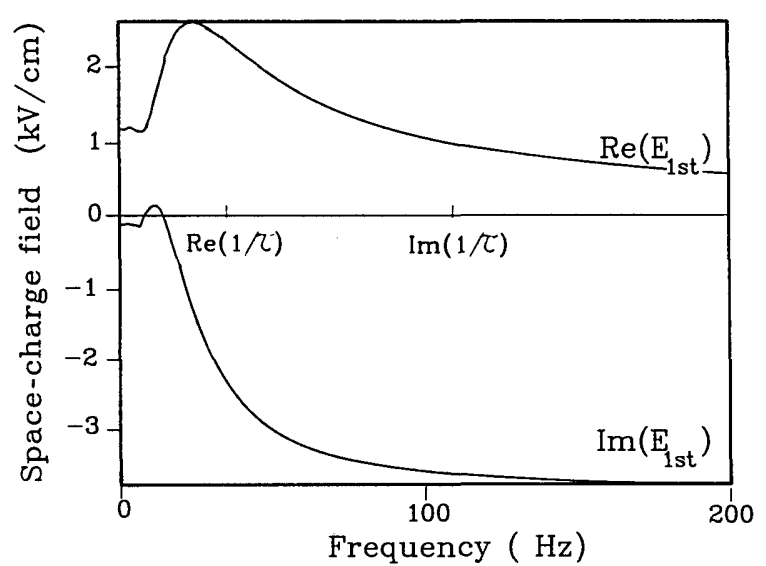

Fig. 2. Real and imaginary parts of the space-charge field versus the applied field frequency for our $\mathrm{Bi}_{12} \mathrm{GeO}_{20}$ sample. The experimental conditions are the same as for curves (b) in Fig. 1.

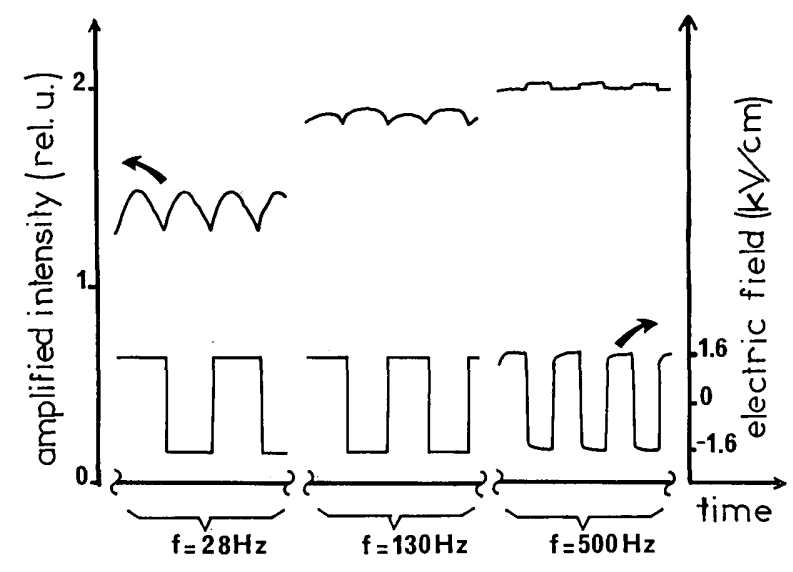

Fig. 3. Periodic behavior of transmitted intensity in relative units [(transmitted intensity with pump beam)/(transmitted intensity without pump beam)] for three different applied field frequencies. The upper curves represent the intensity and correspond to the left axis, while the lower curves represent the applied electric field and correspond to the right axis. The experimental conditions are the same as for curves (b) in Fig. 1.

gain is always positive. We employ the photorefractive parameters measured in our sample and the conventional formula relating the gain to the space-charge field. ${ }^{10-12}$ However, since the optical absorption in our crystal is not negligible $\left(\alpha=1.3 \mathrm{~cm}^{-1}\right.$ at $\lambda=514$ $\mathrm{nm}$ ), the space-charge field is calculated by averaging Eq. (2) (dependent on intensity through $\tau$ ) over the crystal thickness $d=5.9 \mathrm{~mm}$. The relative dielectric constant $\epsilon_{R}=46$ and the electro-optic coefficient $r_{41}=$ $3.4 \mathrm{pm} \mathrm{V} \mathrm{V}^{-1} .15$ The overall agreement between theory and experiment is good.

These results indicate that it is possible to use this amplification technique even if the photorefractive grating time constant $[\operatorname{Re}(1 / \tau)]^{-1}$ is close to the ac field period $T$. This claim is confirmed by the two curves plotted in Fig. 2. These show that for our sample the real part of the space-charge field decreases rapidly as the ac field frequency increases. Therefore, no matter what the intensity, the space-charge electric field is nearly time independent when $T$ is close to $[\operatorname{Re}(1 / \tau)]^{-1}$ [see Eq. (5)]. This behavior is illustrated in Fig. 3, in which the experimental kinetics of the amplified transmitted intensity are represented for field frequencies $f\left(G_{\max } / 2\right)=28 \mathrm{~Hz}, f=130 \mathrm{~Hz}$, and $f\left(G_{\max }\right)=$ $500 \mathrm{~Hz}$. For linearly polarized light, these intensity oscillations are only related to the space-charge field oscillations as described in Ref. 16. The oscillations observed for $f=500 \mathrm{~Hz}$ may be caused by the birefringences induced during the crystal growth ${ }^{16}$ and not by the modulation of the space-charge electric field, which is negligible at this frequency [see Eq. (5)].

In summary, we have analyzed the kinetics of twobeam coupling gain under the influence of a squarewave alternating field. The equations that we have derived in the quasi-continuous regime contribute to the studies previously conducted by other authors. We have shown that the gain may oscillate at twice the applied field frequency. Our study allows us to define a useful frequency range, or an equivalent useful illumination range, for which the gain is nearly time independent and is much more strongly intensified than when an equivalent dc field $\left(E_{\mathrm{dc}}=1.2 \mathrm{kV} / \mathrm{cm}\right)$ is applied.

We are grateful to J. C. Launay of the Laboratoire de Chimie du Solide du Centre National de la Recherche Scientifique, Université de Bordeaux, for supplying the BGO sample.

\section{References}

1. S. I. Stepanov and M. P. Petrov, Opt. Acta 31, 1335 (1984).

2. J. P. Huignard and G. Roosen, in Nonlinear Optics: Materials and Devices, C. Flytzanis and J. L. Oudar, eds. (Springer-Verlag, Berlin, 1986), p. 128.

3. G. Pauliat, J. P. Herriau, A. Delboulbé, G. Roosen, and J. P. Huignard, J. Opt. Soc. Am. B 3, 306 (1986).

4. A. Marrakchi, A. R. Tanguay, J. Yu, and D. Psaltis, Opt. Eng. 24, 124 (1985).

5. S. I. Stepanov and M. P. Petrov, Opt. Commun. 53, 292 (1985).

6. J. Kumar, G. Albanese, and W. H. Steier, J. Opt. Soc. Am. B 4, 1079 (1987).

7. R. B. Bylsma, A. M. Glass, and D. H. Olson, Electron. Lett. 24, 360 (1988).

8. X. Gan, S. Ye, and Y. Sun, Opt. Commun. 66, 155 (1988).

9. C. Besson, J. M. C. Jonathan, A. Villing, and G. Roosen, Proc. Soc. Photo-Opt. Instrum. Eng. 1017, 183 (1988).

10. N. V. Kukhtarev, V. G. Markov, S. G. Odulov, M. S. Soskin, and V. L. Vinetskii, Ferroelectrics 22, 961 (1979).

11. F. P. Strohkendl, J. M. C. Jonathan, and R. W. Hellwarth, Opt. Lett. 11, 312 (1986).

12. G. C. Valley, J. Appl. Phys. 59, 3363 (1986).

13. J. M. C. Jonathan, R. W. Hellwarth, and G. Roosen, IEEE J. Quantum Electron. QE-22, 1936 (1986).

14. G. Pauliat, J. M. C. Jonathan, M. Allain, J. C. Launay, and G. Roosen, Opt. Commun. 59, 266 (1986); 61, 321 (1987).

15. P. V. Lenzo, E. G. Spencer, and A. A. Ballman, Appl. Opt. 5, 1688 (1966).

16. G. Pauliat, C. Besson, and G. Roosen, IEEE J. Quantum Electron. 25, 1736 (1989). 